\title{
Article
}

\section{Expectation of LiDAR on Forest Measurement in Kyoto Protocol}

\author{
Masahiro Amano*
}

\begin{abstract}
Since United Nations Conference on Environment and Development, the world community has formally recognized that forests have a crucial role to play mitigating global warming and it is necessary to evaluate their role through repeatable, verifiable, and transparent scientific data analyses. The Kyoto Protocol and a subsequent document, the Intergovernmental Panel on Climate Change (IPCC) Special Report and Good Practice Guidance for Land Use, Land Use Changes and Forestry, recommended establishing a scientifically neutral method to evaluate and monitor forest land changes and forest biomass dynamics with international standards. Satellite remote sensing has been identified as one tool that can be used to measure forest area, rates of change in land use, location of forest activities, etc. Also satellite data has many advantages that are not only transparent and verifiable but also cost effective, including periodic data acquisition that is internationally available. When negotiators decided the modality of the forest inventory scheme of Kyoto Protocol, they relate it to the imaged characteristics of satellite remote sensing data. But the utility of data from satellites has some difficulties in estimating growing stock changes, and in distinguishing some type of forest activities, such as thinning. In this context LiDAR has a potentiality to provide measures for estimating carbon stock changes, greenhouse gas emissions, and removals associated with forest lands under UNFCCC and Kyoto Protocol. The definition of forest under Kyoto Protocol requires the minimum threshold of forest area, tree crown density, and tree height to be determined within specific ranges. Satellite data have not work well to separate forests according to such a precise threshold. However, LiDAR will be able to provide enough information to judge whether stands will be able to satisfy the definition of a forest. This report discusses the advantages of LiDAR from the view point of the inventory scheme under Kyoto Protocol.
\end{abstract}

Keywords: LiDAR, Kyoto Protocol, Land Use, Land Use Changes and Forestry (LULUCF)

\section{INTRODUCTION}

Since Russia submitted an instrument of ratification for Kyoto Protocol to the United Nations Framework Convention (UNFCCC) on November 18, 2004, the Protocol was entered into force on the 90days later- on February 16, 2005. Japan has promised to reduce annual average of the greenhouse gas (GHG) emissions in the first commitment period of the Kyoto Protocol - from 2008 to 2012 - $6 \%$ less than the GHG emission in 1990. Therefore Japanese Government developed a Kyoto Protocol Target Achievement Plan in April 2005. This Plan

Corresponding author: Masahiro Amano

* School of Human Science, Waseda University

2-579-15 Mikajima, Tokorozawa, Saitama 359-1192

Japan

Tel:+81-4-2947-6740 Fax:+81-4-2947-6801

amano@waseda.jp called for the securing of carbon credit of 13million $\mathrm{t}$ from the forest sector, which is equivalent to $3.8 \%$ of the $6 \%$ overall reduction. However, Japanese greenhouse gas emissions in 2002 had increased $7.6 \%$ above the 1990 level and $8 \%$ more in 2003. Thus, a $14 \%$ reduction from the 2003 greenhouse gas emission levels is required in order to achieve the target. Therefore, it is important to achieve the targets from the forest sector if the overall targets have any chance of being realized.

Of the six greenhouse gases identified in the Kyoto Protocol, $\mathrm{CO}_{2}$ is the gas that is absorbed by the forest. A country's reporting responsibility requires that the calculations be made using the standard established by UNFCCC. This paper considers how LiDAR measurements might contribute to the reporting on the amount of $\mathrm{CO}_{2}$ absorbed by the forest under the UNFCCC requirements. 


\section{BACKGROUND: WHY FOREST IS VALUED IN THE KYOTO PROTOCOL}

Between 1850 and 1998, human activities emitted approximately 270 billion $t$ of carbon through the use of fossil fuel and cement production. Also, land use change, primarily deforestation, generated additional emissions of 136 billion $\mathrm{t}$ of carbon. According to the latest FAO statistics, the area of global forests continued to decline by approximately 12.5 million ha every year in 1990s (FAO, 2001) and the volume of carbon emissions due to land use change is still high. Although the carbon in the atmosphere is sequestrated by ocean and terrestrial ecosystem, the net increased in the atmosphere carbon has been 176 billion $\mathrm{t}$ because the gas emissions exceeded the amount absorbed. In terms of $\mathrm{CO}_{2}$ concentrations in the atmosphere, it increased from $285 \mathrm{ppm}$ to $366 \mathrm{ppm}$ between 1850 and 1998 (IPCC, 2000). It is estimated of the gas emissions due to land use change, $87 \%$ is from conversion of forest land to other purposes, deforestation and forest fire. The remaining $13 \%$ is due to cultivation of field grasses. On the other hand, 2.3 billion $t$ of carbon are absorbed by the land every year. In the terrestrial ecosystem, 466 billion $t$ of carbon is stored in the biomass and 2 trillion $t$ of the carbon is stored in the soil. Reduction of the temperate forests and boreal forests started 5000 years ago in Mediterranean area and China, and a large amount of forests were reduced in North America in the $19^{\text {th }}$ century. However, since later than middle of the $20^{\text {th }}$ century, the forest area has been stable or expanding in North America. In recent years, the volume of the carbon absorbed annually has been 170 million $t$ in the US and of 110million $t$ in the Western Europe. According to FAO statistics, forest in advanced countries absorbed 880 million $\mathrm{t}$ of carbon annually (FAO, 2000). With these facts,

At the insistence of the US and Oceania countries, the carbon absorbed and stored by the forest, field grass, and soil became a part of carbon reductions measured in the Kyoto Protocol. For example, if the forest absorbs 300 thousand $t$ of carbon in the country where its emission reduction target is 1million $t$, the actual amount of emission cuts required is only 700 thousand $t$ of carbon. The role of the forest is addressed in four parts in the Kyoto Protocol: the 3rd and 4th terms of the Article 3, which defines reduction of the greenhouse gas through domestic forests; Article 6, which describes reduction of the greenhouse gas through the cooperation among industrial countries (Annex I countries); and Article 12, which determines reduction of the greenhouse gas through the cooperation between industrial countries and developing countries. Although the articles of the Kyoto Protocol were agreed by COP3 in 1997, the modalities based on these articles were not determined until the 4 years later at Marrakesh Accords (COP7)
Minimum Crown cover 10-30\%

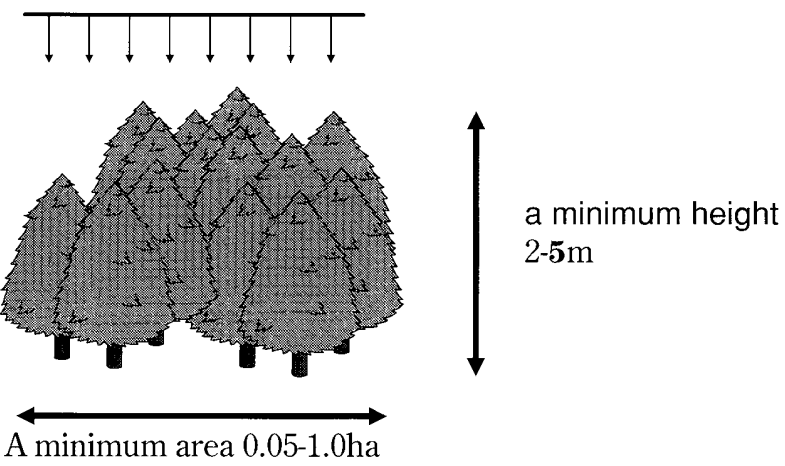

Fig. 1 Definition of Forest under UNFCCC

\section{ITEMS REGARDING FORESTS DETERMINED IN THE KYOTO PROTOCOL}

Definition of the "Forest".

Each country has already determined the definition of the forests by their law, the situations of land uses, and/or the condition of the land coverage. Thus it will be lack of the universal scale in calculation of the absorbed amount of carbon by forest in each country as long as the definition is universally undetermined. As shown in Fig. 1, the Kyoto Protocol requests that each country should formulate the definition of the forest by crown cover, mature tree height, and the minimum area of the forest. However, the threshold values are to be determined within the range shown in the Fig. 1 according to the natural and social conditions of each country.

Direct Human-induced Activity in the Article 3.4

The Article 3.4 describes "The net change in greenhouse gas emissions by sources and removals by sinks resulting from direct human-induced land-use change and forestry activities, limited to afforestation, reforestation and deforestation since 1990, measured as verifiable changes in carbon stocks in each commitment period, shall be used to meet the commitments under this Article of each Party included in Annex I". This article defines "forestation" as the reforestation and/or afforestation on lands that were used for purposes other than forest prior to 1990 . In other words, when the area that had been used for other than the forests as of December 31, 1989 became forest, the average of the changes in carbon stock in 5 years associated with increase or decrease of accumulation in the land from 2008 to 2012 will be considered as amount absorbed or emitted. Regarding reduction in forests, when the forest as of December 31, 1989 is changed to an alternative land use forest before December 31, 2012, the average of the changes in carbon stock on the land in each year between 2008 and 2012 will be recorded. In the case 
where the forest persists, the forest is treated as absorbing the carbon. However, if severe forest thinning and final cutting are implemented between 2008 and 2012 and the storage in 2012 is less than the storage in 2008 , this situation will be considered as an emission. In the former case where forest land has been converted to agriculture, there are no large changes made in the carbon stock with the time passed, unlike the forest, and therefore the carbon balance will be reported as "zero".

Additional Human-induced Activity in the Article 3.4

The Article 3.4 targets the greenhouse gas reduction through acceleration of the carbon sequestration capacity by adding the human-induced activities to the existing forests while the Article 3.3 describes the evaluation of the absorbed amount of the forest newly established. With the precondition of application mainly from the second commitment period, the Article 3.4 of the Protocol describes "The Conference of the Parties serving as the meeting of the Parties to this Protocol shall, at its first session or as soon as practicable thereafter, decide upon modalities, rules and guidelines as to how, and which, additional human-induced activities related to changes in greenhouse gas emission by sources and removals by sinks in the agricultural soils and the land-use change and forestry categories shall be added to, or subtracted from, the assigned amounts for Parties ". However, concrete modalities are not included in the Protocol. Also, there is a sentence in the end of the $4^{\text {th }}$ Terms of the Article 3, "A Party may choose to apply such a decision on these additional human-induced activities for its first commitment period, provided that these activities have taken place since 1990." In the Marrakesh Accords developed by COP7, the additional human-induced activity includes a. vegetation restoration, $\mathrm{b}$. agricultural land management, c. grass field management, d. forest management. If there is any additional activity desired to apply in the first commitment period, it shall be selected and reported. Japan considers the forest management as an essential item for achievement of the reduction target.

There were various discussions regarding how to determine the activity as the forest management, and for the tentative target limited to the first commitment period, it reached the consensus on the forest with any human-induced activities after 1990 as the source of absorption. However, the contents of the human-induced activities are not discussed at the negotiating scene of Kyoto Protocol. There are various perspectives that some countries consider that the forest stands covered by the forest planning and the forests in the area with fire prevention taken are subjected to the forest management activity to satisfy Kyoto Protocol. Some countries consider only forests with actual specific operations, such as thinning, weeding and fertilizer activities implemented after 1990, shall be subjected to forest management activities that satisfy Kyoto. Since this is a politically sensitive issue and forest operations differ depending on the natural and social environments in each country, the current view is that the decision on the standards and definitions be left to each country. Also, the current view is that the evaluations are to be conducted by the countries and will determine whether the evaluation decision would be appropriate at the time that the inventory report is received by the secretariat office of the United Nations Framework Convention on Climate Change (UNFCCC).

\section{EXPECTATION OF LIDAR MEASUREMENT ON KYOTO PROTOCOL}

For the evaluation of forest $\mathrm{CO}_{2}$ absorption in the Kyoto Protocol, the negotiator's first concern was the utilization of satellite remote sensing technique. The Protocol requires the measurement with transparent and verifiable method and report, at the same time, if the remote sensing data are used, it is easy to ensure the transparency and to verify the result obtained. However, there are some problems that would not be solved by the satellite data alone and that occurred in the process of establishment of the concrete rules such as the regulations in the 3 rd and 4 th terms of the Article 3 . These regulations require the measurement not only of above-ground biomass but also debris on the ground, below-ground biomass and soil carbon, some of which are impossible to be measured by satellite remote sensing tools. The author is expecting the resolution of many problems by complementary utilization of the LiDAR, which may work as regional/national sampling tool to provide detail forest resource profiling, and swath sampling data, which include proxies of each carbon pool requested by Kyoto Protocol. Major points are as follows.

\section{Utilization of LiDAR for Definition of Forest}

Japan is planning to determine for three thresholds of forest definitions as following; the minimum area of the forest is $0.3 \mathrm{ha}$, the crown cover is $30 \%$, and tree height is about $5 \mathrm{~m}$. The negotiators of each country who have been involved in preparation of the Protocol thought that these forests would be easily categorized by the satellite remote sensing technique. However, using only spectral information, it is difficult to determine the forest area where the crown cover of $30 \%$ is strictly the threshold value and there are various tree species. Also, 3D data are required for determining the tree height data. However, it's relatively easy to lay out the tree crown and other gap parts, and to calculate the average forest stand height in terms of the study example to which the LiDAR is applicable. In addition, one of key factors needed to get good estimation of tree height and differentiate forests with specific crown cover is a size of footprint of LiDAR 
Afforestation, Reforestation and Deforestation in the Article 3.3 and LiDAR Utilization

It has been assumed that to detect areas of afforestation, reforestation and deforestation would be easy using satellite remote sensing data. However, it's actually difficult to differentiate the young forests with tree height of $1-2 \mathrm{~m}$ after the operations of afforestation and reforestation from the grass field and farm land. Also, it's found that there were many misinterpretations for differentiation between temporary bare land after harvest and that following replanting or conversion of land use to other purposes. This suggests that it is difficult to determine changes in the land coverage or the land use by the satellite remote sensing data alone, although general satellite remote sensing data easily detects many changes in the land coverage. These considerations suggest that continuous monitoring of the afforestation, reforestation and deforestation of the specific location after 1990 will be impossible with the sound accuracy of the current satellite remote sensing data in the business-level. Therefore the forests with the afforestation, reforestation and deforestation will need to be collected as administrative information, at least for a while.

If the LiDAR will be able to detect the terrain properly where the remaining materials of the forest land are built along the contour lines for afforestation, and young forests regularly planted, the detection of afforestation, reforestation and deforestation with the remote sensing will be easy.

Utilization of LiDAR for Additional Human-induced Activity under the Article 3.4

Article 3.4 addresses forests that are sequestering carbon, i.e., forest zones, and forests that are losing carbon through, for instance, thinning. In Japan, the forested area that is periodically thinned is large relative to that forested area that is completely harvested and reforested. It is necessary to determine the difference in the number of standing trees in order to differentiate whether the forests are thinned or not. As with crown cover, it is not easy to estimate the number of standing trees by the satellite remote sensing data. However, the estimation of the stand density using the LiDAR is not difficult. In this case it is possible to differentiate the thinned forests and the forests without thinning, from the relation between the tree height and the stand density,

\section{FUTURE OF KYOTO PROTOCOL AND REMOTE SENSING}

Even though the administrative data and conventional forest inventory system are utilized for the report in the first commitment period, there is no choice but to establish the new remote sensing data-oriented reporting system in consideration of transparency and verifiability for the second session. Besides the report to the Protocol, agriculture and forests are reported separately in the national inventory for the greenhouse gas emission of the UNFCCC. However, in the guidelines to be revised in 2006, the national land will be divided into six land uses and be reported collectively. Also, any changes made in the land use shall be reported separately. Therefore monitoring of the land use on a nationwide scale is necessary and the guideline emphasizes utilization of the remote sensing techniques. Regarding the forest sector, a report of the $\mathrm{CO}_{2}$ absorption with a high accuracy will be available if the measurement of the change in forestry biomass by the LiDAR is periodically undertaken. Judging from the trend of current negotiation, e.g., a report is required every 5 years, the dependence on the ground survey is not rational in terms of data collection and processing. Therefore establishment of the forest biomass monitoring system, which is a combination of permanent monitoring plots with remote sensing by LiDAR, is desired.

\section{ACKNOWLEDGEMENT}

The author gratefully thanks for Dr. Roger Sedjo of the Resources for the Future, Washington DC, US. He provided helpful comments on this manuscript. This work was supported by the Global Environment Research Fund of the Ministry of Environment, Japan.

\section{LITERATURE CITED}

FAO, (2000): Forest Resources of Europe, CIS, North America, Australia, Japan and New Zealand, United Nations, 158pp

FAO, (2001): Global Forest Resources Assessment 2000, FAO, 9pp

IPCC, (2000): Land Use, Land-Use Changes, and Forestry, Cambridge University Press, $5 \mathrm{pp}$

Hori, S., Hayashi, H., Amano, M., Matsumoto, M. and Awaya, Y., (2002): Development of ARD determination in the Article 3.4 using satellite data, Aerial Photogrammetry for Forest, 197: 1-7 (in Japanese) 